\title{
Operational Efficiency of the Football Team in Chinese Super League with DEA
}

\author{
Wei $\mathrm{Xu}^{1}$ \\ ${ }^{1}$ College of Economics and Management, Nanjing University of Aeronautics and Astronautics, Nanjing, China \\ Correspondence: Wei Xu, College of Economics and Management, Nanjing University of Aeronautics and \\ Astronautics, Nanjing, Jiangsu, China.
}

Received: December 26, 2017

Accepted: January 15, 2018

Online Published: February 2, 2018

doi:10.5539/ibr.v11n3p1

URL: https://doi.org/10.5539/ibr.v11n3p1

\begin{abstract}
With the professionalization of Chinese football, currently, Chinese football industry has become a new economic topic. The team like Guangzhou Evergrande, as a representative of the 'money' football policy in China, is popular. The China Football Association Super League (CSL) can be considered as an emerging field of great investment value. As such, the team's operational efficiency should be a key factor that affects the managers and investors. Based on the input-oriented Data Envelope Analysis (DEA) model, this study analyzes the operational efficiencies of teams in CSL. The empirical study shows three key findings: First, team using the crazy investment mode is not efficient in 2012, 2013, 2014 seasons. Second, Beijing Guoan's efficiency declined in the 2015 season due to his few investment. Third, in order to achieve good achievements in the league in the future, increasing investment should be an inevitable choice.
\end{abstract}

Keywords: Chinese super league, operational efficiency, DEA

\section{Introduction}

Chinese Football Super League, organized by the Chinese Football Association, is the highest level of professional football league in mainland china. The league was established in 2004 and it contains 16 clubs since 2008. Before 2009, Chinese Football League suffered long-term management corruption and gambling. These problems have attracted the attention of related leaders, including the supreme leader Xi Jingping. Then the Ministry of Public Security carried out the 'Anti-Gambling Action in Football Games'. In 2011, Guangzhou Evergrande, one of the clubs in Chinese Premier League spared few expense to buy a big name. after the anti-gambling controversy, Chinese football once again attracted the attention of people around the world. Since then, Guangzhou Evergrande introduced high level foreign players, employed high level coaches, constructed a professional club management mode, etc. As a result, it has ruled the CSL for several years, by the end of the season in 2017, it has achieved the champion in CSL for seven times, and twice Champion in the Asian Football Confederation (AFC) Champions League. Evergrande's impressive record has led to the transformation of other clubs' operation modes. Currently, the overall efficiency of these clubs' operations has become a problem worthy of studying.

Researchers have studied operational efficiency of sport clubs around the world. For instance, Hoefler and Payne (2006) discussed the team efficiency of National Basketball Association (NBA) in 2001-2002 based on a stochastic frontier approach (SFA). Other studies, such like Yang et al. (2014), Moreno et al. (2014), Radovanovic et al. (2014), etc., have also made great contribution in this field.

Data Envelope Analysis (DEA) has been widely applied in studies of football club's performance. Haas (2003) uses DEA-CCR model and DEA-BBC model to analyze the efficiencies of the 12 teams in the major league of the United States in 2000. they also calculate the efficiencies of the 20 teams in the Premier League. Barros and Leach (2006) evaluate the performances of the English Premier Football League based on a DEA model. Barros and Garcia-Del-Barrio (2008) utilize a SFA model to study the efficiency of each team in the Premier League.

Compared with other countries, there is a lack of research on football clubs' operational efficiencies in China. Due to the late construction of Chinese professional football league, each team's data about cost and profit are not always available. In this study, we collect related data about clubs during 2012-2015. The performances of those football clubs are then evaluated by a DEA model. 


\section{Method}

Data envelopment analysis (DEA) model is a methodology for the purpose of calculating efficiencies in production. Researches on the three most basic models and their applications include: (1) Standard CRS and VRS-DEA models outlined in Färe et al. (1994) (2) Färe et al. (1994) expanded these models to evaluate cost and allocative efficiencies. (3) The application of Malmquist DEA methods in panel data analysis to calculate indices of total factor productivity (TFP) change, first researched by Fare et al. (1994). DEA involves the use of linear programming methods to construct a non-parametric piecewise surface (or frontier) over the data, so as to be able to calculate efficiencies relative to this surface. In this study, the DEAP2.1 software is utilized to calculate CRS DEA model and VRS DEA model.

\subsection{Measuring the DEA Efficiency}

Farrell (1957) defines a simple measure of firm efficiency which could account for multiple inputs. It has two components: The technical efficiency (TE), which reflects the ability of the decision making unit to maximize the output of the given input; Allocative efficiency (AE), reflected in the price of a given input, evaluates the ability to use the unit with an optimal ratio of investment. The combination of these two measures provides a measure of total economic efficiency. He gives a simple example to show that under the condition of constant returns to scale, the yield curve of the complete efficiency unit. Technology inefficiency is represented by the distance of QP in figure 1, which shows that the proportional reduction of all inputs with a constant output.

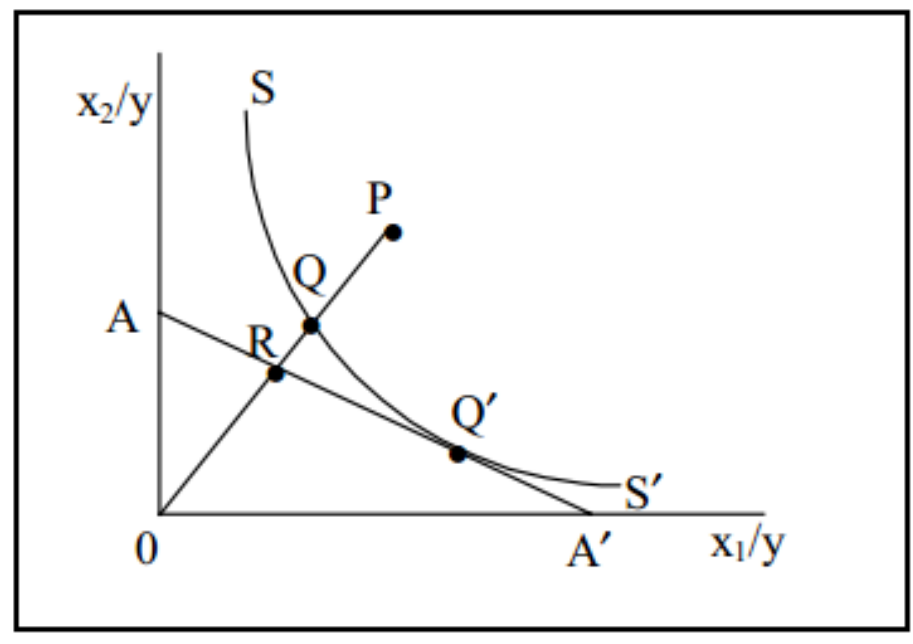

Figure 1. Technical and Allocative Efficiencies

In figure 1, QP/OP shows the percentage by which each input could be reduced. The technical efficiency of a unit is usually represented by a ratio of $\mathrm{OQ} / \mathrm{OP}$, which provides an indicator of technical inefficiency. The line $\mathrm{AA}^{\prime}$ is utilized to show the ratio between prices of inputs, the allocation efficiency can then be calculated by $\mathrm{AE} 1=\mathrm{OR} / \mathrm{OQ}$. RQ here represents the cost saved when production occurred in the effective allocation or effective technical point Q' instead of the ineffective point Q. Economic efficiency is calculated by EE1=OR/OP, $\mathrm{RP}$ could also be used to represent the cost. According to the definition, these three kinds of efficiency are between 0 and 1 . Input oriented efficiency evaluates the ratio by which the inputs could be reduced by when output is constant. Another measure is the ratio by which the output could be raised when the inputs are constant. This is the output oriented efficiency measurement.

\subsection{Input-oriented DEA Model with Constant Return of Scale}

The purpose of DEA is to construct a non-parametric envelope frontier around data points, so that all the observed points are in or under the production frontier.

We can construct a ratio form DEA model to search for the best value of $u^{\prime} y_{i} / v^{\prime} x_{i}$ as shown in (1). This is a LP model, where $\mathrm{u}, \mathrm{v}$ are the weight vectors, $\mathrm{x}$ is the input vector. $\mathrm{y}$ is output vector.

$$
\begin{aligned}
& \max _{u, v}\left(u^{\prime} y_{i} / v^{\prime} x_{i},\right) \\
& \text { st } u^{\prime} y_{i} / v^{\prime} x_{i} \leq 1, i=1,2, \ldots, N,
\end{aligned}
$$




$$
\mathrm{u}, \mathrm{v} \geq 0 \text {. }
$$

After transformation, we can derive an equivalent envelopment form of this problem, as shown in (2),

$$
\begin{gathered}
\min _{\theta, \lambda} \theta \\
\text { st }-y_{i}+Y \lambda \geq 0, \\
\theta x_{i}-X \lambda \geq 0, \\
\lambda \geq 0
\end{gathered}
$$

here $\Theta$ is the efficiency score of firm i. It equals to 1 when the unit is on the frontier, so it is an efficient decision making unit (DMU).

\subsection{Input-oriented DEA with variable return of Scale and Scale Efficiency}

In CRS model, if the DMU is not in the optimal scale of operation, scale efficiency(SE) might disturb the measurement of TE. VRS model then could avoid the impact of SE on TE calculation. Take the convex constraints into consideration, CRS could be easily converted to a VRS model shown in (3), where $\mathrm{N} 1$ is an $\mathrm{N} \times 1$ vector of ones.

$$
\begin{gathered}
\min _{\theta, \lambda} \theta \\
\text { st }-\mathrm{y}_{\mathrm{i}}+\mathrm{Y} \lambda \geq 0, \\
\theta \mathrm{x}_{\mathrm{i}}-\mathrm{X} \lambda \geq 0, \\
\mathrm{~N} 1^{\prime} \lambda=1 \\
\lambda \geq 0,
\end{gathered}
$$

TE calculated by CRS, which is shown in (4), could be decomposed into scale efficiency and pure technical efficiency. The differences between VRS based TE and CRS based TE could be calculated by (4).

$$
\mathrm{TE}_{\mathrm{I}, \mathrm{CRS}}=\mathrm{TE}_{\mathrm{I}, \mathrm{VRS}} \times \mathrm{SE}_{\mathrm{I}}
$$

The following NIRS model, shown in (5), reflects the DEA efficiency with non-increasing returns to scale.

$$
\begin{gathered}
\min _{\theta, \lambda} \theta \\
\text { st }-\mathrm{y}_{\mathrm{i}}+\mathrm{Y} \lambda \geq 0, \\
\theta \mathrm{x}_{\mathrm{i}}-\mathrm{X} \lambda \geq 0, \\
\mathrm{~N} 1{ }^{\prime} \lambda \leq 1 \\
\lambda \geq 0
\end{gathered}
$$

As shown in figure 2, if the NIRS based TE of the DMU is not equal to the value of VRS, there is an increasing return to scale. On the other hand, if they are equal, then there is a decreasing returns to scale. As shown in figure 2 , there is an increasing returns to scale in point $\mathrm{P}$, while returns to scale is decreasing in point $\mathrm{Q}$. 


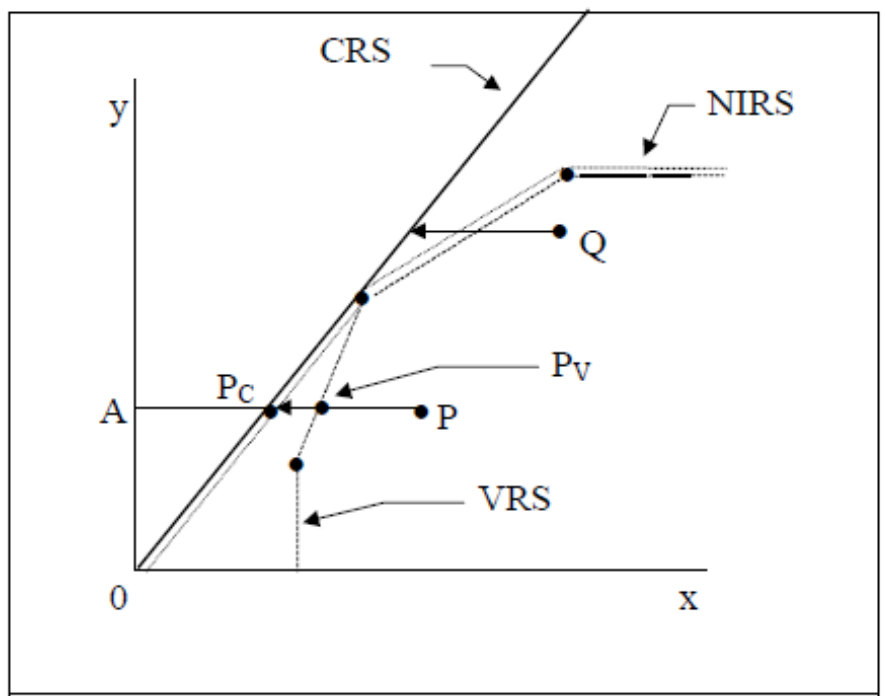

Figure 2. Calculation of Scale Economies in DEA

Finally, according to Li and Chen (2003), we could generate application steps.

Determine the purpose of evaluation

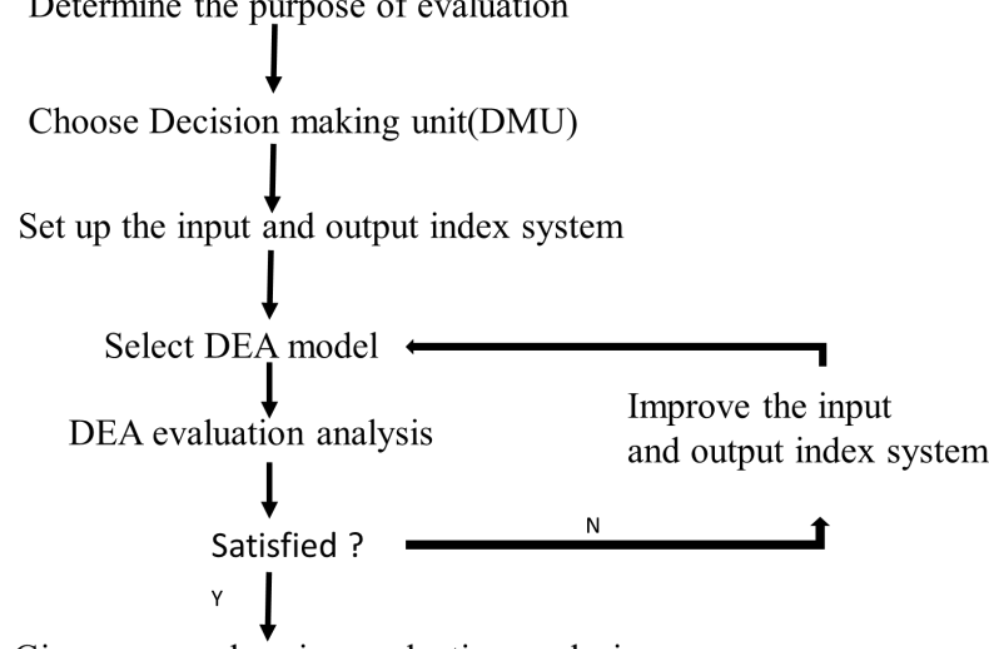

Give a comprehensive evaluation analysis

Figure 3. Application steps for DEA

\section{Variable Setting and Data Sources}

In order to keep the studied teams at the same level and study the changes in different season, our study selects the non-degraded teams and AFC Champions League teams in the past four seasons (in 2012, 2013, 2014 and 2015).

The team's input indicators mainly include player wages, transfer fees, coach costs, operating expenses and other costs. Team's outputs include ticket income, attendance, team record, market value and team influence.

Considering the availability of data, this paper selects the employee wages and transfer fees as the input indicators. The costs of different teams in Super League clubs are not released officially, and the only way we can obtain is estimation from the information in the related news and website. The employee wages are reckoned on the urban per capita disposable income of the teams' provinces or municipalities, which are available in China Statistical Yearbook. Different clubs determine their own transfer fees. Some can make a lot of money, while some need to pay a lot. The transfer fees of different teams can be positive or negative. It will be positive when buying a player and negative when selling a player. However, the DEA model requires that all the inputs must be positives, and we need to make some transform properly. Similar to the idea of decision theory, we can keep it nonnegative by the transform that let the transfer fee of different teams minus the smallest one. 
We select the team influence and total market capitalization as the output indicators. As it is hard to quantify team influence, we use BAIDU news search data such as '2012 Guangzhou Evergrande' to represent it. The transfer fee and total market capitalization are available in the website of transfermakt.com ${ }^{1}$, which is a website in German that publishes the information about team scores, transfer news, player values and some other things. Despite the fact that the value of players does not match the actual situation, researchers at the Center of Economic Performance estimate that the rumor about player transfer fee is basically accurate. For example, the input-output table in 2015 is summarized as table 1.

Table 1. Inputs and outputs of CSL teams in 2015

\begin{tabular}{lllll}
\hline Teams & \multicolumn{1}{c}{$\begin{array}{c}\text { Y1 } \\
\text { (times) }\end{array}$} & $\begin{array}{c}\text { Y2 } \\
\left(10^{\wedge} 4 \mathrm{euros}\right)\end{array}$ & $\begin{array}{c}\text { X1 } \\
\left(10^{\wedge} 4 \mathrm{euros}\right)\end{array}$ & $\begin{array}{c}\text { X2 } \\
(\mathrm{rmb})\end{array}$ \\
\hline Shanghai Shenhua & 13600 & 1668 & 2302 & 53670.61 \\
Guangzhou Evergrande & 758000 & 2398 & 4453 & 33749.98 \\
Beijing Guoan & 45700 & 1195 & 1268 & 55477.7 \\
Guangzhou R\&F & 465000 & 990 & 1300 & 33749.98 \\
Shandong Luneng Taishan & 38000 & 2123 & 653 & 31351.95 \\
Beijing Renhe & 51800 & 1339 & 0.1 & 24769.96 \\
Tianjin Teda & 520000 & 850 & 1105 & 33031.13 \\
Liaoning FC & 14400 & 405 & 693 & 32397.74 \\
Jiangsu Sainty & 21900 & 908 & 1158 & 37098.96 \\
Hangzhou Greentown & 1370 & 423 & 531.5 & 43781.26 \\
Changchun Yatai & 13800 & 910 & 972 & 25047.25 \\
Shanghai Shenxin & 4070 & 588 & 335 & 53670.61 \\
\hline
\end{tabular}

In table 1, X1 represents transfer fee, and it has been transferred to keep nonnegative. X2 is the teams' employee wages. Y1 represents the team influence shown in BAIDU search engine. Y2 is the total market capitalization of every team. In order to ensure that the model can be solved, we change the value 0 in the table to 0.1 .

The study uses the input-oriented VRS-DEA model with variable returns to scale, and the parameter settings in DEAP 2.1 are shown in Table 2. In order to avoid the problem of inefficiency due to the excessive input when the discrete possible linear production curve is parallel to the axis, we adopt the multi-stage DEA method in the calculation of slack variables.

Table 2. Parameter settings in DEAP 2.1

\begin{tabular}{cc}
\hline Parameter & Setting \\
\hline number of firms & 12 \\
number of time periods & 1 \\
number of inputs & 2 \\
number of outputs & 2 \\
oriented & input orientated \\
return of scales & variable return of scales \\
stages & multi-stage \\
\hline
\end{tabular}

\section{Empirical Analysis}

\subsection{Technical Efficiency, Scale Efficiency Analysis of League Teams}

First, we calculated the annual relative efficiency of all teams remains in CSL, the results are shown in table 3-6.

Table 3. Relative efficiencies of CSL teams in the 2015 season

\begin{tabular}{lcccc}
\hline Team & crste & vrste & scale & \\
\hline Shanghai Shenhua & 0.455 & 0.513 & 0.886 & irs \\
Guangzhou Evergrande & 1 & 1 & 1 & - \\
Beijing Guoan & 0.33 & 0.446 & 0.738 & irs \\
Guangzhou R\&F & 0.915 & 0.941 & 0.973 & irs \\
Shandong Luneng Taishan & 1 & 1 & 1 & - \\
Beijing renhe & 1 & 1 & 1 & - \\
Tianjin Teda & 1 & 1 & 1 & irs \\
Liaoning FC & 0.192 & 0.765 & 0.251 & irs \\
Jiangsu Sainty & 0.36 & 0.668 & 0.539 & irs \\
Hangzhou Greentown & 0.156 & 0.566 & 0.275 & irs \\
Changchun Yatai & 0.532 & 0.989 & 0.538 & irs \\
Shanghai Shenxin & 0.188 & 0.462 & 0.408 & 0.717 \\
Mean & 0.594 & 0.779 & & \\
\hline
\end{tabular}

\footnotetext{
${ }^{1}$ https://en.wikipedia.org/wiki/Transfermarkt
} 
Table 4. Relative efficiencies of CSL teams in the 2014 season

\begin{tabular}{lcccc}
\hline Team & crste & vrste & scale \\
\hline Shanghai Shenhua & 1 & 1 & 1 & - \\
Guangzhou Evergrande & 0.117 & 0.229 & 0.511 & irs \\
Beijing Guoan & 1 & 1 & 1 & - \\
Guangzhou R\&F & 0.179 & 0.679 & 0.263 & irs \\
Shandong Luneng Taishan & 0.213 & 1 & 0.213 & drs \\
Beijing renhe & 0.506 & 0.554 & 0.914 & irs \\
Tianjin Teda & 0.473 & 1 & 0.473 & irs \\
Liaoning FC & 1 & 1 & 1 & - \\
Jiangsu Sainty & 0.221 & 0.739 & 0.299 & irs \\
Hangzhou Greentown & 0.457 & 0.949 & 0.482 & irs \\
Changchun Yatai & 0.021 & 0.731 & 0.029 & irs \\
Shanghai Shenxin & 1 & 1 & 1 & - \\
mean & 0.516 & 0.823 & 0.599 & \\
\hline
\end{tabular}

Table 5. Relative efficiencies of CSL teams in the 2013 season

\begin{tabular}{lcccl}
\hline Team & crste & vrste & scale & \\
\hline Shanghai Shenhua & 0.507 & 0.539 & 0.941 & irs \\
Guangzhou Evergrande & 0.324 & 0.331 & 0.979 & drs \\
Beijing Guoan & 1 & 1 & 1 & - \\
Guangzhou R\&F & 0.511 & 0.515 & 0.992 & drs \\
Shandong Luneng Taishan & 0.126 & 0.242 & 0.519 & irs \\
Beijing Renhe & 0.207 & 0.383 & 0.539 & irs \\
Tianjin Teda & 0.713 & 1 & 0.713 & irs \\
Liaoning FC & 1 & 1 & 1 & - \\
Jiangsu Sainty & 0.485 & 0.555 & 0.874 & irs \\
Hangzhou Greentown & 0.682 & 0.725 & 0.941 & irs \\
Changchun Yatai & 0.872 & 0.946 & 0.922 & irs \\
Shanghai Shenxin & 0.354 & 0.706 & 0.501 & irs \\
mean & 0.565 & 0.662 & 0.827 & \\
\hline
\end{tabular}

Table 6. Relative efficiencies of CSL teams in the 2012 season

\begin{tabular}{lcccc}
\hline team & crste & vrste & scale \\
\hline Shanghai Shenhua & 0.143 & 1 & 0.143 & drs \\
Guangzhou Evergrande & 0.126 & 0.126 & 0.996 & irs \\
Beijing Guoan & 1 & 1 & 1 & - \\
Guangzhou R\&F & 0.034 & 0.154 & 0.221 & irs \\
Shandong Luneng Taishan & 0.083 & 0.249 & 0.333 & irs \\
Beijing Renhe & 0.491 & 0.502 & 0.979 & irs \\
Tianjin Teda & 1 & 1 & 1 & - \\
Liaoning FC & 0.56 & 0.618 & 0.906 & irs \\
Jiangsu Sainty & 0.834 & 0.857 & 0.973 & irs \\
Hangzhou Greentown & 1 & 1 & 1 & - \\
Changchun Yatai & 0.704 & 0.758 & 0.929 & irs \\
Shanghai Shenxin & 0.251 & 1 & 0.251 & irs \\
mean & 0.519 & 0.689 & 0.728 \\
\hline
\end{tabular}

Based on the results shown in table 3-6, the so-called 'Big 3', namely Guangzhou Evergrande, Beijing Guoan, Shandong Luneng, all have great investments and Guangzhou Evergrande has achieved all the champions during these 5 years. However, it is DEA effective only in the 2015 season. In the other seasons, its scale efficiency is better than many clubs, while its pure technical efficiency (vrste) and the total efficiency (crste) are both much lower ${ }^{2}$. There are two possible reasons for this phenomenon. On the one hand, the attraction of CSL is not high during that time. On the other hand, the CSL is less competitive during those years. It is then not needed to invest too much. Or we can say that during that time the champion is not depend so much on the investment.

Beijing Guoan ranges first in accordance with the operational efficiency, it ran well in 2012, 2013 and 2014 seasons. In the 2015 season, its investment scale is not large enough. Under the actual investment scale, its pure technical efficiency has not reached the best. According to the league process during 2015 season, Beijing Guoan's investment is not large. It does not have a deep enough bench strength. this resulted in that they have no competitive players affordable to play. They also finally lost the qualification for the next AFC Champions League. It used to be one of the AFC Champions League teams between 2012 and 2014.

The efficiencies of Shandong Luneng in the 2012 and 2013 seasons are very low. By the end of 2012 season, it

\footnotetext{
${ }^{2}$ Note: crste $=$ vrste $*$ scale
} 
even dropped to tenth in CSL. In the 2013 season, its pure technical efficiency is 1, while its scale efficiency is less than 1. This means that there is no need to reduce the investment or increase the output in accordance with $\mathrm{TE}$ of the sample unit. The reason why the comprehensive efficiency of the sample unit is not effective (equals to 1 ) is that its scale is not match its input and output. It is then needed to decrease the scale. There is a decreasing returns of scale in the 2014 season. Luneng has then achieved its best relative efficiency during recent period in 2015. In such an increasingly fierce competitive league environment, relying on youth talent and competitive foreign players, Luneng can still maintain a strong competitiveness in CSL.

\subsection{Slack and Radial Movement Analysis of CSL Teams}

We take the Jiangsu Sainty team as an example to analyze the slack and radial movement. The performances of Jiangsu Sainty during 2012-2015 are shown in table 7.

Table 7. Input and output of Jiangsu Sainty during 2012 to 2015

\begin{tabular}{|c|c|c|c|c|c|}
\hline & variable & original value & radial movement & slack movement & projected value \\
\hline \multirow[t]{4}{*}{2015} & Output1 & 21900 & 0 & 29900 & 51800 \\
\hline & Output2 & 908 & 0 & 431 & 1339 \\
\hline & Input1 & 1158 & -384.835 & -773.065 & 0.1 \\
\hline & Input2 & 37098.96 & -12329 & 0 & 24769.96 \\
\hline \multirow[t]{4}{*}{2014} & Output1 & 16 & 0 & 0 & 16 \\
\hline & Output2 & 200 & 0 & 407.807 & 607.807 \\
\hline & Input1 & 505 & -131.623 & 0 & 373.377 \\
\hline & Input2 & 747 & -194.697 & 0 & 552.303 \\
\hline \multirow[t]{4}{*}{2013} & Output1 & 16 & 0 & 7.5 & 23.5 \\
\hline & Output2 & 700 & 0 & 0 & 700 \\
\hline & Input1 & 870 & -387 & 0 & 483 \\
\hline & Input2 & 986 & -438.6 & -276.85 & 270.55 \\
\hline \multirow[t]{4}{*}{2012} & Output1 & 12 & 0 & 230.481 & 242.481 \\
\hline & Output2 & 700 & 0 & 0 & 700 \\
\hline & Input1 & 430 & -61.334 & 0 & 368.666 \\
\hline & Input2 & 458 & -65.328 & 0 & 392.672 \\
\hline
\end{tabular}

As shown in table 7, in the 2012 season, Jiangsu Sainty achieved the best relative efficiency during those seasons. It also reached the second place in the league, which is also the best record in the team's history. However, with the whole investment of CSL teams becoming more and more big, Jiangsu team's investment is then relatively not enough. It then suffers a subsequent decline in the ranking during the next season. The club's market value is also declined.

According to table 7, in the 2015 season, the first output and the second output of Jiangsu team are both insufficient. This means the market value and social influence or reputation of the team are not great enough. There are redundancies in both the team's first input and second input. To be specific, the first input redundancy and second input redundancy are 1158 and 12329 respectively. It means that the performance in that season could be achieved with less transfer fee and smaller employees' salaries. Although the League performance is poor, Jiangsu Sainty has achieved the football association cup in 2015, which has incentivized the manager to increase investment in the following season.

\subsection{Efficiency Analysis of AFC Champions League Teams}

In addition, we also analyze the performance of CSL teams that have attended the AFC Champions League. The results are shown in table 8 .

In table 8, the performances of AFC Champions League teams are evaluated based on given indexes. Based on the comparison between these teams, it is not always true that the efficiency of teams with better performance is better. For example, Beijing Guoan had the best operational efficiencies in 2012, 2013, 2014, it also performs well in the AFC Champions League, but there was a decline in its operational efficiency in 2015.

Between 2012 and 2014, the annual performances of Guangzhou Evergrande reflected his deep pockets through increasing investment to achieve the champions. This mode of operation should not be said to be bad as the current successful club Guangzhou Evergrande is resulted from the accumulation investment during those period.

It is interesting that, compared with those 'big 3' teams, the other teams who have attended the AFC Champions League have the best annual relatively efficiencies. To be specific, Tianjin Teda has the best efficiency in 2012, Jiangsu Sainty has the best efficiency in 2013, Beijing Guoan has the best efficiency in 2014, Guangzhou R \& F has the best efficiency in 2015. It is significant for those teams striving for the inspiration. Increasing the operational efficiency could be more important than making a huge investment. In this way, they could also 
avoid the 'arms race' in the league. After all, not all teams have the ability to compete with the 'big 3' in financial investment.

Table 8. Operational efficiency of AFC champion league teams

\begin{tabular}{|c|c|c|c|c|c|}
\hline Season & Team & crste & vrste & scal & \\
\hline \multirow{5}{*}{2015} & Guangzhou Evergrande & 1 & 1 & 1 & - \\
\hline & Beijing Guoan & 0.336 & 0.566 & 0.594 & irs \\
\hline & Shandong Luneng Taishan & 1 & 1 & 1 & - \\
\hline & Guangzhou R\&F & 1 & 1 & 1 & - \\
\hline & mean & 0.834 & 0.891 & 0.898 & \\
\hline \multirow[t]{5}{*}{2014} & Guangzhou Evergrande & 0.121 & 0.475 & 0.254 & irs \\
\hline & Beijing Guoan & 1 & 1 & 1 & - \\
\hline & Shandong Luneng Taishan & 0.509 & 1 & 0.509 & drs \\
\hline & Beijing Renhe & 1 & 1 & 1 & - \\
\hline & Mean & 0.657 & 0.869 & 0.691 & \\
\hline \multirow[t]{5}{*}{2013} & Guangzhou Evergrande & 0.342 & 0.681 & 0.502 & irs \\
\hline & Beijing Guoan & 1 & 1 & 1 & - \\
\hline & Beijing Renhe & 0.505 & 0.876 & 0.576 & irs \\
\hline & Jiangsu Sainty & 1 & 1 & 1 & - \\
\hline & Mean & 0.712 & 0.889 & 0.77 & \\
\hline \multirow[t]{4}{*}{2012} & Guangzhou Evergrande & 0.196 & 1 & 0.196 & drs \\
\hline & Beijing Guoan & 1 & 1 & 1 & - \\
\hline & Tianjing Teda & 1 & 1 & 1 & - \\
\hline & Mean & 0.732 & 1 & 0.732 & \\
\hline
\end{tabular}

4.4 Slack and Radial Movement Analysis of AFC Champion League Teams

We also analyze the slack and radial movement of AFC Champions League teams. For instance, table 9 and table 10 have shown the input and output of Beijing Guoan in AFC Champion League and CSL in 2015 respectively.

Table 9. Input and output of Beijing Guoan in AFC 2015

\begin{tabular}{lcccc}
\hline Variable & original value & radial movement & slack movement & $\begin{array}{c}\text { projected } \\
\text { value }\end{array}$ \\
\hline Output1 & 45700 & 0 & 0 & 45700 \\
Output2 & 1195 & 0 & 930.941 & 2125.941 \\
Input1 & 1268 & -550.833 & -23.528 & 693.639 \\
Input2 & 55477.7 & -24100.1 & 0 & 31377.59 \\
Technical efficiency & 0.566 & & & \\
Scale efficiency & $0.594 \quad$ (irs) & & & projected value \\
\hline Table 10. Input and output of Beijing Guoan in CSL 2015 & slack movement & 51800 \\
\hline Variable & original value & radial movement & 6100 & 1339 \\
\hline Output1 & 45700 & 0 & 144 & 0.1 \\
Output2 & 1195 & 0 & -566.043 & 24769.96 \\
Input1 & 1268 & -701.857 & 0 & \\
Input2 & 55477.7 & -30707.7 & & \\
Technical efficiency & 0.446 & & & \\
Scale efficiency & 0.738 (irs) & & & \\
\hline
\end{tabular}

Comparing the measured operational efficiencies of Beijing Guoan with teams in AFC Champion League and CSL, Guoan's pure technical efficiency is relatively high, and its scale efficiency is low. Comparing with the AFC Champions League teams, it is lack of second output, which means its market value is not enough. The first and second input is both redundant, meaning that its transfer fee is too high, without any significant improvement in its operational efficiency. Comparing with the CSL team, the first output, i.e. its social influence or reputation is not good enough. Similarly, transfer and employee performance have not achieved the desired target, resulting in a low overall efficiency.

\section{Conclusion}

We use input-oriented Data envelopment analysis (DEA) model to analyze the operational efficiency of different teams in Chinese Super League. This paper selects the employee wages and transfer fees as input indicators, and the team influence and total market value as output indicators. The empirical study shows that:

First, in fact, the crazy investment of Guangzhou Evergrande has not promoted its operational efficiency, but led the league's competitiveness. Intense competition is also a kind of exercise and growth for Guangzhou Evergrande, which has made it the best efficient one in the 2015 season.

Second, among the 'big 3' teams, Guoan's efficiency has declined greatly, if it could not enlarge the investment, 
it would suffer a lot in the following season.

Third, considering the development of the CSL, increasing investment is an inevitable choice to achieve good performances for the teams in the future. However, enlarging the investment would not necessarily lead to a good performance in the league. It is also quite important to increase the operational efficiency, especially for those clubs that could not afford for as large investment as the 'big 3' teams.

\section{Reference}

Barros, C. P., \& Garcia-Del-Barrio, P. (2008). Efficiency measurement of the english football premier league with a random frontier model. Economic Modelling, 25(5), 994-1002. https://doi.org/10.1016/j.econmod.2008.01.004

Barros, C. P., \& Leach, S. (2006). Performance evaluation of the english premier football league with data envelopment analysis. Applied Economics, 38(12), 1449-1458. https://doi.org/10.1080/00036840500396574

Färe, R., Grosskopf, S., \& Lovell, C. A. K. (1994). Production frontiers. Cambridge University Press.

Färe, R., Grosskopf, S., \& Norris, M. (1994). Productivity growth, technical progress, and efficiency change in industrialized countries: reply. American Economic Review, 84(5), 1040-1044.

Farrell, M. J. (1957). The measurement of productive efficiency. Journal of the Royal Statistical Society, 120(3), 253-290. https://doi.org/10.2307/2343100

Haas, \& Dieter, J. (2003). Productive efficiency of english football teams. a data envelopment analysis approach. Managerial \& Decision Economics, 24(5), 403-410.

Hofler, R. A., \& Payne, J. E. (2010). Efficiency in the national basketball association: a stochastic frontier approach with panel data. Managerial \& Decision Economics, 27(4), 279-285. https://doi.org/10.1002/mde.1252

Li, M., \& Chen, G. (2003). A review on the research and application of DEA. Engineering Science, 5(6), 88-94.

Moreno, P., \& Lozano, S. (2014). A network dea assessment of team efficiency in the nba. Annals of Operations Research, 214(1), 99-124. https://doi.org/10.1007/s10479-012-1074-9

Radovanovic, S., Radojicic, M., \& Savic, G. (2014). Two-phased dea-mla approach for predicting efficiency of nba players. Yugoslav Journal of Operations Research, 24(3), 347-358. https://doi.org/10.2298/YJOR140430030R

Yang, C. H., Lin, H. Y., \& Chen, C. P. (2014). Measuring the efficiency of nba teams: additive efficiency decomposition in two-stage dea. Annals of Operations Research,217(1), 565-589. https://doi.org/10.1007/s10479-014-1536-3

\section{Copyrights}

Copyright for this article is retained by the author(s), with first publication rights granted to the journal.

This is an open-access article distributed under the terms and conditions of the Creative Commons Attribution license (http://creativecommons.org/licenses/by/4.0/). 